\title{
Erratum to: Environmentally induced programmed cell death in leaf protoplasts of Aponogeton madagascariensis
}

\author{
Christina E. N. Lord • \\ Arunika H. L. A. N. Gunawardena
}

Published online: 15 December 2012

(C) Springer-Verlag Berlin Heidelberg 2012

\section{Erratum to: Planta (2011) 233:407-421 \\ DOI 10.1007/s00425-010-1304-9}

The authors have noted an error in image selection for the introductory figure (Fig. 1). Therefore a new image has been provided below. All information in the existing text of the published article was unchanged. The authors apologize for this error.
Fig. 1 The lace plant (Aponogeton

madagascariensis). a Window stage lace plant leaf, displaying transparent windows where PCD is occurring. b Perforation expansion lace plant leaf portraying the expansion of the perforated areole. c Mature lace plant leaf showing completed perforations between longitudinal and transverse veins. d Sterile lace plant in magenta box. Scale bars $100 \mu \mathrm{m}(\mathbf{a}-\mathbf{c}), 1 \mathrm{~cm}(\mathbf{d})$
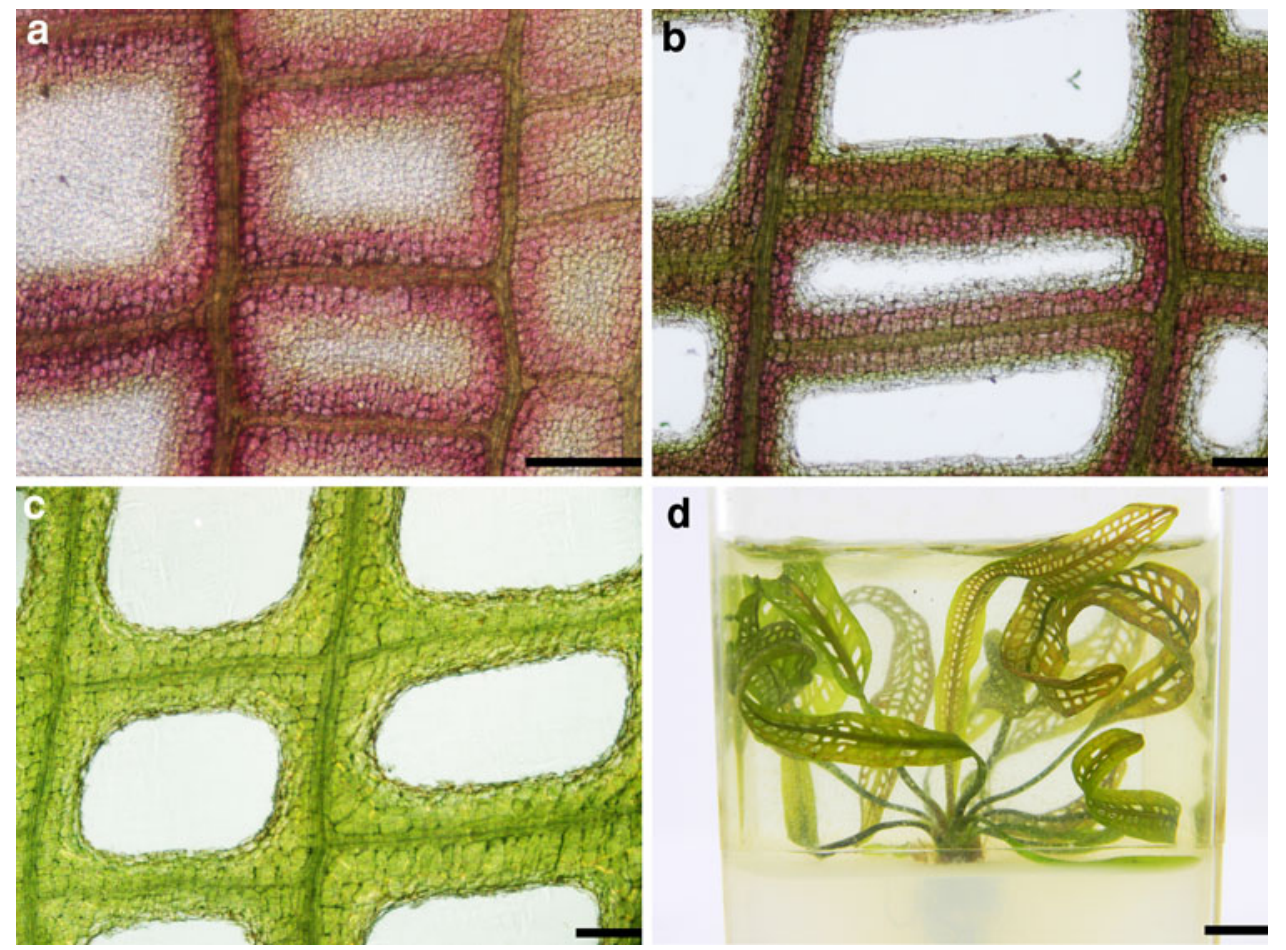

The online version of the original article can be found under doi:10.1007/s00425-010-1304-9.

C. E. N. Lord · A. H. L. A. N. Gunawardena ( $₫)$

Department of Biology, Dalhousie University,

1355 Oxford Street, Halifax, NS B3H 4J1, Canada

e-mail: arunika.gunawardena@dal.ca

C. E. N. Lord

e-mail: celord@dal.ca 